\title{
Application of Trimp in Training Monitoring of Competitive Sports
}

\author{
Minghui Luo* and Yunyu Tu \\ College of Physical Education, GanNan Normal University, China
}

\begin{abstract}
Trimp is a scientific method which starts from modern exercise training theory to make precise control over load. It can calculate load effectively, It is well applied in economic sports events, and lays a solid theoretical basis to improve athletes' athletic capabilities.
\end{abstract}

Keywords: Competitive sports, training monitoring, trimp.

\section{INTRODUCTION}

To improve athletic performance, the relevant personnel can properly enhance training strength, so as to ensure the direct external stimulus, these factors can be summarized as external factors which affect athlete' s body. Load is the main factor for controlling exercise training, and the specific content of load is carried out according to different training conditions and changes with it. In the theory of modern training, load is not only a kind of external stimulus but also includes physiological and psychological response when body is affected in different ways.

In traditional physiological change index, only through stimuli can the body affect the physiological response, and then detailed loads are further determined. The relevant personnel should integrate all biochemical indexes to monitor their trainings. Although this method can make a record, it cannot reflect exercise loads. Therefore, the relevant personnel should have an all-round knowledge of different training items, environment and the range of action of physiological and biochemical indexes.

\section{COMMON TRIMP MODE}

Trimp is a kind of calculation method. However external loads change, the relevant personnel only need to see the internal loads of athletes. Traditionally, only training loads are considered, the influence of other external stimuli on internal loads of athletes is ignored [1]. However, Trimp includes all external loads and gets internal loads, which completely reflects athletes' adaption to loads and can reflect actual exercise loads better (see Fig. 1).

\subsection{HR-based Trimp}

Trimp (Training impulse) was firstly presented by Banister and his peers in 1975. The theory is based on that HR will change with the change of exercise intensity and exercise time [1]. It seems to reflect body's response to actual stimuli.
Table 1. Relationship between Trimp and \%HRmax by Edwards, etc.

\begin{tabular}{|c|c|}
\hline Weight Factor & \%HRmax \\
\hline \hline 1 & $51-61$ \\
\hline 2 & $61-71$ \\
\hline 3 & $71-81$ \\
\hline 4 & $81-91$ \\
\hline 5 & $91-100$ \\
\hline
\end{tabular}

The initial calculation formula is Trimp $=$ exercise time $\mathrm{x}$ exercise intensity, and it is mainly applied to calculate the load of durable endurance exercise.

The initial load assessment is only used for the product of average heart rate and exercise time, but the simple formula has a lot of problems and cannot completely reflect the actual load borne by athletes. It does not consider the different response of male and female athletes when suffering from same load and cannot reflect the difference of athletes at different levels when suffering same load, especially when assessing high-level athletes and high intensity exercise [2]. To make Trimp calculation easy and consider the need of calculating intermittent exercise, Edwards and his peers introduced heart rate zone into calculation. When calculating, the weight factor of the zone where the exercise center rate is locate at (Table 1) should multiply by exercise time, and total Trimp should be the sum of all zone Trimps.

Recently, Earnest and his peers and Lucia and peers divided HR zone into three zones with significant signs (see Table 2) according to the oxygen uptake of body in increasing load or metabolism of lactic acid, which was called Lucia.s Trimp by Impellizzeri, etc. In calculation, the model also utilizes the product of zone weight index and time. The calculation formula of total Trimp is also the sum of all zone Tirmps. Different from Edwards who uses the fixed heart rate zone, Lucia and his peers utilize the lab test data of athletes. 


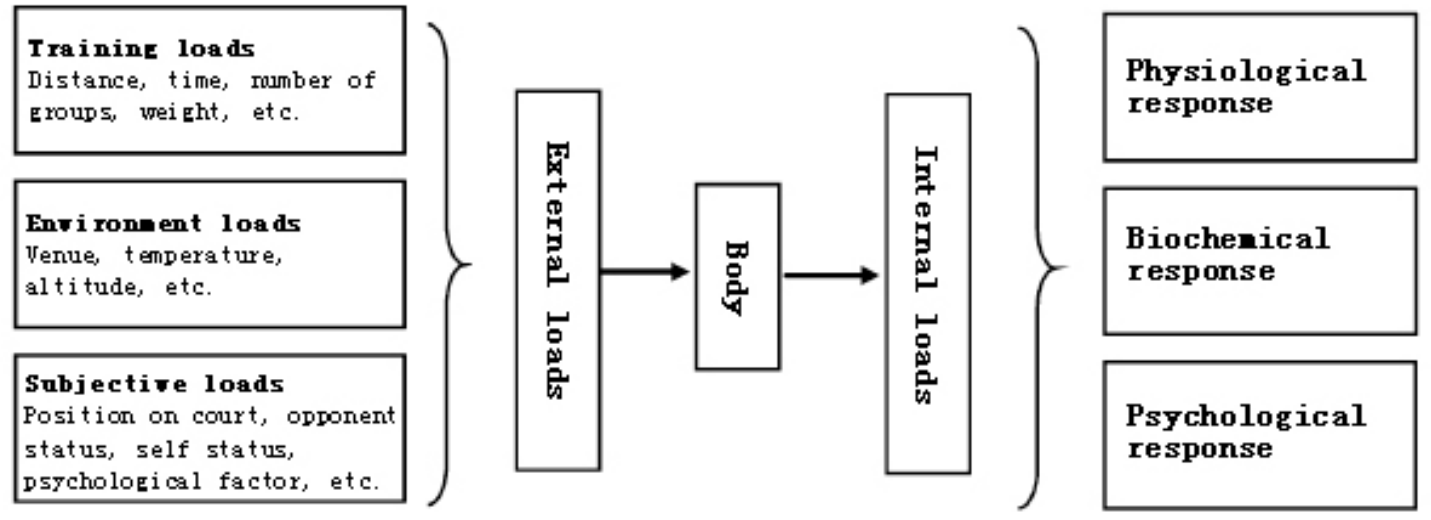

Fig. (1). Relationship diagram of internal and external loads.

Table 2. Zone division sign of lucia method.

\begin{tabular}{|c|c|c|c|}
\hline Weight Factor & Bla & \%VO2max & VO2max \\
\hline \hline 1 & $<2.5 \mathrm{~mol} / 1$ & $<70 \%$ & $<$ VO2 breath compensatory point \\
\hline 2 & $2.5-4 \mathrm{~mol} / 1$ & $70 \%-90 \%$ & $\begin{array}{c}\text { VO2 breath compensatory point }- \\
\text { VO2 ventilatory threshold }\end{array}$ \\
\hline 3 & $>4 \mathrm{~mol} / 1$ & $>90 \%$ & $>$ VO2 ventilatory threshold \\
\hline
\end{tabular}

Because of heart rate daytime aberrance, the heart rate monitoring cannot completely reflect exercise intensity. Since athletes are influenced by exercise status, environment, hydration status and exercise time, the relevant personnel's analysis on the heart rate of athletes will result in high cost, which makes HR-based Trimp difficult in promotion [3].

\subsection{RPE-based Trimp}

To simplify calculation of exercise loads or measurement of exercise intensity, Foster et al. developed Session RPE method (see Table 3) to replace HR method, and verified that session RPE method is highly related to HR and lactic acid method in calculating exercise intensity. Session RPE method considers the min post-exercise subjective value. The calculation formula is the product of session RPE value and exercise time, and the total Trimp is the sum of all zone Trimps.

Table 3. Table of RPE values.

\begin{tabular}{|c|c|}
\hline Level & Subjective Feeling \\
\hline \hline 0 & Quiet \\
\hline 1 & Very relaxed \\
\hline 2 & Simple \\
\hline 3 & Moderate \\
\hline 4 & A little difficult \\
\hline 5 & Difficult \\
\hline
\end{tabular}

Therefore, session RPE model cannot completely replace the Trimp calculation method based on heart rate, because that these scores have poor effectiveness in calculating exercise intensity [4], and RPE is the comprehensive subjective response of athletes after influenced by all factors, such as hormone content (catecholamine), content of metabolic substrates (carbohydrate, glycogen and lactic acid), personal willpower, respiratory rate, nerve conduction velocity, environmental factor, and psychological status. These factors may restrict RPE to correctly assess exercise intensity and exercise loads.

\section{APPLICATION OF TRIMP IN COMPETITIVE SPORTS}

\subsection{Calculation of Exercise Loads}

According to modern theory of sports training, exercise loads refer to not only external loads but also a series of responses of athletes when being influenced by factors. In different training phases, the training loads are different. So the training situation or external conditions of athletes should be improved properly, so as to avoid big changes of internal loads [5].

Trimp is developed after load control. It mainly calculates the actual exercise loads borne by athletes and is a comprehensive response to external loads of athletes. See Table 4 for details.

From the table above, it is observed that there is difference in calculation between traditional exercise load and Trimp load. The difference value of Trimp value is 174 in the competition with exercise time difference of $2 \mathrm{~min}$, and Trimp value has a big difference in distance. Hence, in the 
Table 4. Difference in load calculation between traditional method and trimp load calculation.

\begin{tabular}{|c|c|c|c|c|c|}
\hline \multirow[t]{2}{*}{ Competition } & \multirow[t]{2}{*}{ Player } & \multicolumn{3}{|c|}{ Traditional Load Calculation Method } & \multirow{2}{*}{ Trimp Method } \\
\hline & & Rank & Time & Distance & \\
\hline \multirow[t]{2}{*}{ National championship } & A & 1 & $1: 46$ & \multirow{2}{*}{$33.4 \mathrm{~km}$} & 467.2 \\
\hline & B & 3 & $1: 57$ & & 751.2 \\
\hline \multirow[t]{2}{*}{ World championship } & A & 21 & $2: 11$ & \multirow{2}{*}{$37.4 \mathrm{~km}$} & 644.2 \\
\hline & B & 15 & $1: 54$ & & 633.1 \\
\hline
\end{tabular}

same competition, the difference in athlete status and road condition will cause big influence on Trimp [6]. The relevant personnel should combine actual situation and take a reasonable loading way to avoid error in load calculation. Trimp assesses exercise status and external loads, so as to ensure that the calculated value can better reflect the actual exercise loads of athletes.

In group events, because of the difference in the position and exercise venue, an athlete may have different status in competition. Trimp can reflect the load and exercise intensity of athletes in a good manner. According to the study on ice hockey, the intensity of competition is higher than that of exercise. In this study, different exercise courts and different positions in court of athlete in football events will affect Trimp value.

According to the study, after long-time training, athlete's weekly Trimp value has no relation with training time, intensity, total load and training method. Therefore, the relevant personnel should select reasonable Trimp values. Day Trimp value can divide the exercise load control in a more detailed manner and avoid error.

\subsection{Monitoring Overtraining}

Athletes can adapt to exercise stress by bearing stimuli constantly, and improve exercise capacity by this way. If athletes cannot adapt to such exercise loads and such exercise loads exceed group adaptive capacity, tiredness accumulation of athletes will be caused, and overtraining will further be formed. Such phenomenon is caused by overtraining load [7]. The relevant personnel should analyze athletes' maximum load according to actual situation and take effective measures to solve those problems. According to the study, the exercise capacity of athletes will see a distinct decline if athletes are overtrained for long time. Therefore, such phenomenon should be restricted as far as possible.

Trimp is the result repeatedly integrated during the load training of athletes. Overtraining will make athletes have high stress and their Trimp values are distinctly different from that of normal athletes. In the study, the Trimp values of overtraining athletes are $40 \%$ higher than that of normal athletes, and that values decline by $60 \%$ after proper adjustment. According to long-term analysis, if weekly Trimp exceeds 4,000 hours, most of athletes will be ill at different levels. By tracing and analyzing the exercise of mountain bike athletes for long time, the relevant personnel find that their body and exercise capacity see a decline at different levels if overtrained. On same racing track, their Trimp values are different and even $44 \%$ higher than that in normal status.

\section{CONCLUSION AND OUTLOOK}

To improve exercise achievements, athletes take highintensity exercise, however, the improvement in exercise achievements is related to the exercise load of body, and the load capacity of athletes directly influences their professional skill level. In this process, the relevant personnel should have an all-round knowledge of the calculation methods of athlete load, plan exercise contents reasonably, and make scientific arrangements, so as to avoid athletes' being overtrained for long and timely master and integrate the exercise status of athletes.

Currently, foreign study on Trimp is mature while seldom domestic study on it is made. In different environment, Trimp calculation methods are different. Such method can be used to correctly calculate the actual load of athletes. But the method is defective in high intensity and the complex calculation. Thus the relevant personnel shall combine specific condition and integrate mass data for study, so as to ensure the accuracy of this method.

\section{CONFLICT OF INTEREST}

The authors confirm that this article content has no conflict of interest.

\section{ACKNOWLEDGEMENTS}

Declared none.

\section{REFERENCES}

[1] N. Zhu, S. Lei, and P. Cao, "Application of Trimp in Training Monitoring of Competitive Sports," Sports and Science, no.2, pp. 117-118, 2011.

[2] Y. Xiao, C. Han, and Q. Wang, "Study on Training Mode of Competitive Sports Based on System Control," Journal of Qufu Normal University (Natural Science Edition), no.4, pp. 162-163, 2014.

[3] H. Xun, and H. He, "Prospect and Application of Thermalism in Training of Competitive Sports," Chinese Journal of Convalescent Medicine, no.9, pp. 137-138, 2014.

[4] M. Luo, X. Chen, and J. Ouyang, "Study on the Application of Hemoglobin Index in Training Monitoring of Competitive Dragon Dance," Journal of Xi'an University of Arts \& Science (Natural Science Edition), no.3, pp. 179-180, 2009. 
[5] Q. He, "Investigation and Analysis on Training Monitoring of Chinese Teenager Amateurish Sports," Journal of Xinxiang University (Science), no.4, pp. 139-140, 2013.

[6] S. Chen, "The Role of Human Movement Science in Competitive Sports," Journal of Linyi University, no.3, pp. 105-106, 2012.
[7] Z. Zhang, "Study, Development and Application of Sport Psychology in Competitive Sports," Journal of Tianjin University of Sport, no.3, pp. 169-170, 2012.

Received: June 10, 2015

Revised: July 29, 2015

Accepted: August 15, 2015

(C) Luo and Tu; Licensee Bentham Open.

This is an open access article licensed under the terms of the (https://creativecommons.org/licenses/by/4.0/legalcode), which permits unrestricted, noncommercial use, distribution and reproduction in any medium, provided the work is properly cited. 